\title{
Sistem Pakar Penentuan Kualitas Garam di Desa Sedayulawas Kabupaten Lamongan Menggunakan Metode Forward Chaining
}

\author{
Fadhli Almu'iini Ahda ${ }^{1}$, Gandes Nawang Sari $^{2}$, Lia Farokhah \\ Institut Teknologi dan Bisnis Asia Malang \\ 1'fadhlial@asia.ac.id, ${ }^{2}$ gandes.ns@gmail.com, ${ }^{3}$ lia.farokhah@gmail.com
}

\begin{abstract}
ABSTRAK. Garam merupakan salah satu kebutuhan yang menjadi pelengkap dari kebutuhan pangan, dan merupakan sumber elektrolit bagi tubuh manusia. Garam banyak dimanfaatkan sebagai bumbu dapur dalam rumah tangga, pembuatan kosmetik, kaca, dan lain sebagainya. Pembuatan garam dilakukan dengan meratakan petak tambak yang sudah diisi air laut dan dengan bantuan sinar matahari air laut ini mengkristal dan menjadi butiran-butiran garam. Proses ini berlangsung rutin pada musim kemarau di daerah (pesisir) penghasil garam, dari bulan Juni hingga bulan November atau mulai turunnya hujan pada awal Desember, yang menjadi permasalahan petani garam adalah bagaimana cara menentukan kualitas garam tersebut. Dalam menentukan kualitas garam, sistem pakar digunakan untuk menentukan kualitas tersebut. Untuk itu metode yang digunakan adalah Forward Chaining. Metode ini dipilih karena mampu menentukan kualitas berdasarkan fakta yang ada yaitu seperti warna garam, rasa garam, dan bentuk garam. Dengan teknik pencarian fakta kemudian mencocokkan fakta tersebut dengan bagian IF, maka rule dieksekusi dan sebuah fakta baru THEN dan diimplementasikan dengan pemrograman berbasis web dan ditambahkan kedalam database MySQL untuk membantu pengolahan data. Setelah melakukan perancangan dan implementasi dari permasalahan, maka pengujian dilakukan dengan menggunakan black box.Pengujian ini untuk membuktikan sistem pakar untuk menentukan kualitas garam sudah sesuai dengan yang diharapkan yaitu mencapai $100 \%$.
\end{abstract}

Keywords: sistem pakar, kualitas garam, metode Forward Chaining, rule-based, black box.

ABSTRACT. Salt is one of the needs that complement food needs, and is a source of electrolytes for the human body. Salt is widely used as a spice in the household, making cosmetics, glass, and so forth. Making salt is done by leveling the ponds that have been filled with sea water and with the help of sunshine this sea water crystallizes and becomes granules of salt. This process takes place routinely in the dry season in the salt-producing (coastal) area, from June to November or starting to rain in early December, the problem with salt farmers is how to determine the quality of the salt. In determining the quality of salt, an expert system is used to determine the quality. For that the method used is Forward Chaining. This method was chosen because it is able to determine the quality based on available facts, such as the color of salt, the taste of salt, and the shape of salt. With the fact finding technique and then matching that fact with the IF section, the rule is executed and a new fact is THEN and implemented with web-based programming and added to the MySQL database to assist data processing. After designing and implementing the problem, the test is carried out using a black box. This test is to prove the expert system to determine the quality of salt in accordance with the expected that reaches $100 \%$.

Keywords: expert system, salt quality, Forward Chaining method, rule-based, black box

\section{PENDAHULUAN}

Indonesia sebagai negara kepulauan dengan panjang garis pantai $81.000 \mathrm{~km}$ merupakan kawasan pesisir dan lautan yang memiliki berbagai sumber daya hayati dan non-hayati yang sangat besar. Dengan lautan yang merupakan $70 \%$ dari luasan total negara, maka laut menyimpan banyak potensi untuk dimanfaatkan, antara lain adalah garam.

Garam banyak dimanfaatkan sebagai bumbu dapur dalam rumah tangga, pembuatan kosmetik, kaca, dan lain sebagainya. Pembuatan garam dilakukan oleh pentani garam dengan cara meratakan petak tambak yang sudah diisi air laut dan dengan bantuan sinar matahari air laut ini mengkristal dan menjadi butiranbutiran garam. Proses ini berlangsung rutin pada musim kemarau di dareah (pesisir) penghasil garam, dari bulan Juni hingga bulan November atau mulai turunnya hujan pada awal Desember.

Yang menjadi permasalahan bagi petani garam adalah bagaimana cara menentukan kualitas garam tersebut. Sedangkan untuk menentukan kualitas harus melakukan pengecekan kandungan garam di laboratorium terlebih dahulu dan dilakukan secara berulang-ulang dengan di dampingi seorang pakar.

Untuk membantu menyelesaikan masalah di atas tersebut, maka diperlukan sistem yang membantu untuk menentukan kualitas garam dengan lebih mudah dan efisien sehingga petani mampu mengambil keputusan diwaktu yang singkat dan cepat dalam menetukan kualitas garam.

Dengan adanya kemajuan teknologi yang semakin pesat, telah berkembang suatu teknologi yang mampu mengadopsi proses dan cara pikir manusia yaitu kecerdasan buatan atau Artificial Intellegence (AI). 
Artificial Intelligence (AI) memiliki berbagai macam aplikasi, salah satunya adalah sistem pakar. Sistem pakar merupakan program Artificial Intelligence (AI) yang menggabungkan basis pengetahuan dengan inference engine. Program ini bertindak sebagai seorang konsultan yang cerdas atau penasehat dalam suatu lingkungan keahlian tertentu.

Sistem pakar (Expert System) dapat memberikan informasi dan juga sebagai sistem yang memberikan konsultasi untuk mengetahui kualitas garam. Berdasarkan uraian permasalahan di atas maka penulis memberi solusi dari permasalahan tersebut dengan membuat sebuah sistem dengan nama "Sistem PakarPenentuan Kualitas Garam Di Desa Sedayulawas Kabupaten Lamongan Menggunakan Metode Forward Chaining".

\section{METODE}

\subsection{Analisa Permasalahan}

Sistem ini merupakan sistem yang dikembangkan untuk membuat analisis terhadap data untuk mengetahui kualitas pada garam. Dalam sistem ini digunakan metode forward chaining untuk mengklasifikasikan ciri-ciri garam yaitu warna garam, rasa garam dan bentuk garam yang di-input-kan sehingga diketahui kualitas dari garam tersebut.

Sistem pakar yang dibangun merupakan sistem yang merepresentasikan kemampuan atau keahlian seorang pakar atau orang yang berpengalaman dibidang tertentu untuk membantu pengguna dalam mengatasi masalah dalam menentukan kualitas garam.

Perancangan sistem pakar menentukan kualitas garam dengan metode forward chaining dapat dikategorikan sebagai masalah artificial intelligence khususnya sistem pakar karena pemecahan masalah tersebut dapat dilakukan dengan pengembangan sistem yang dapat berperan sebagai seorang ahli atau pakar

\subsection{Analisa Data Garam}

Data-data garam didapatkan dari observasi yang dilakukan di PUGAR (Pemberdayaan Usaha Garam Rakyat) di Desa Sedayulawas yaitu berupa tabel jenis garam yaitu garam konsumsi dan garam industri, tabel ciri-ciri garam yaitu warna garam, rasa garam dan bentuk garam, tabel kesimpulan yang berisi kualitas garam KW 1 (Baik), KW 2 (Kurang Baik), KW 3 (Buruk), dan garam kosmetik/farmasi, tabel data ciri-ciri dari masing-masing kualitas beserta kandungan dari ciri-ciri garam tersebut.

Data-data ini telah disusun dalam bentuk tabel untuk mendukung sistem yang akan dibuat dan nantinya dapat menjadi acuan pada pembuatan sistem pakar. Untuk lebih jelas dapat dilihat pada tabel sebagai berikut:

\subsubsection{Data Jenis Garam dan Ciri-ciri Garam}

Tabel 1. Data Jenis Garam

\begin{tabular}{|c|c|}
\hline Kode & \multicolumn{1}{|c|}{ Jenis } \\
\hline J001 & Garam Konsumsi (makanan) \\
\hline J002 & Garam Industri (non makanan) \\
\hline
\end{tabular}

Tabel 2. Data Ciri-ciri Garam

\begin{tabular}{|l|l|}
\hline Kode & Ciri-ciri \\
\hline C001 & Warna putih bening kering \\
\hline C002 & Warna putih bening basah \\
\hline C003 & Warna putih kapur kering \\
\hline C004 & Warna putih kapur basah \\
\hline C005 & Warna kemerahan basah \\
\hline C006 & Warna kecoklatan basah \\
\hline C007 & Warna kehitaman basah \\
\hline C008 & Rasa asin garam \\
\hline
\end{tabular}




\begin{tabular}{|l|l|}
\hline C009 & Rasa asin ringan \\
\hline C010 & Rasa asin pahit \\
\hline C011 & Rasa pahit \\
\hline C012 & Bentuk segi empat \\
\hline C013 & Bentuk tajam \\
\hline
\end{tabular}

Dari jenis garam dan ciri-ciri garam diatas dapat dilihat pada tabel dibawah yaitu berupa kesimpulan yaitu kualitas yang telah ditentukan oleh pakar yang berisi ciri-ciri dan kandungannya.

\subsubsection{Flowchart Forward Chaining}

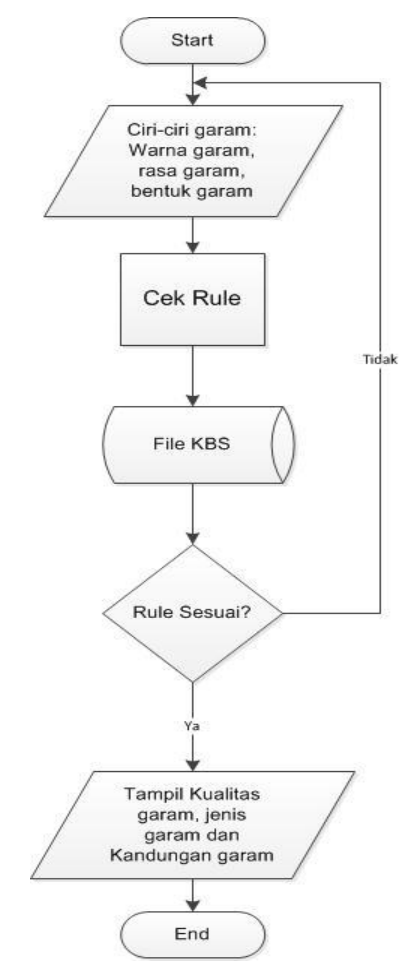

Gambar 1. Flowchart Inferensi Forward Chaining

\subsubsection{Membuat Knowlegde Base System}

Langkah-langkah membangun KBS (Knowledge Base System) dalam metode Forward Chaining menggunakan tahapan sebagi berikut

Tabel 3. Plan Set 1-4

\begin{tabular}{|l|l|l|}
\hline \multicolumn{1}{|c|}{ Condition: } & & Number Of Values \\
\hline Warna Putih Bening Kering & (Yes, No) & 2 \\
\hline Warna Putih Bening Basah & (Yes, No) & 2 \\
\hline Warna Putih Kapur Kering & (Yes, No) & 2 \\
\hline Warna Putih Kapur Basah & (Yes, No) & 2 \\
\hline Warna Kemerahan Basah & (Yes, No) & 2 \\
\hline Warna Kecoklatan Basah & (Yes, No) & 2 \\
\hline Warna Kehitaman Basah & (Yes, No) & 2 \\
\hline Rasa Asin Garam & (Yes, No) & 2 \\
\hline Rasa Asin Ringan & (Yes, No) & 2 \\
\hline Rasa Asin Pahit & (Yes, No) & 2 \\
\hline
\end{tabular}




\begin{tabular}{|l|l|l|}
\hline Rasa Pahit & (Yes, No) & 2 \\
\hline Bentuk Segi Empat & (Yes, No) & 2 \\
\hline Bentuk Tajam & (Yes, No) & 2 \\
\hline Row & $\mathbf{=}^{\mathbf{1 3}}$ & $\mathbf{= 8 1 9 2}$ \\
\hline
\end{tabular}

\subsubsection{Dependency Diagram}

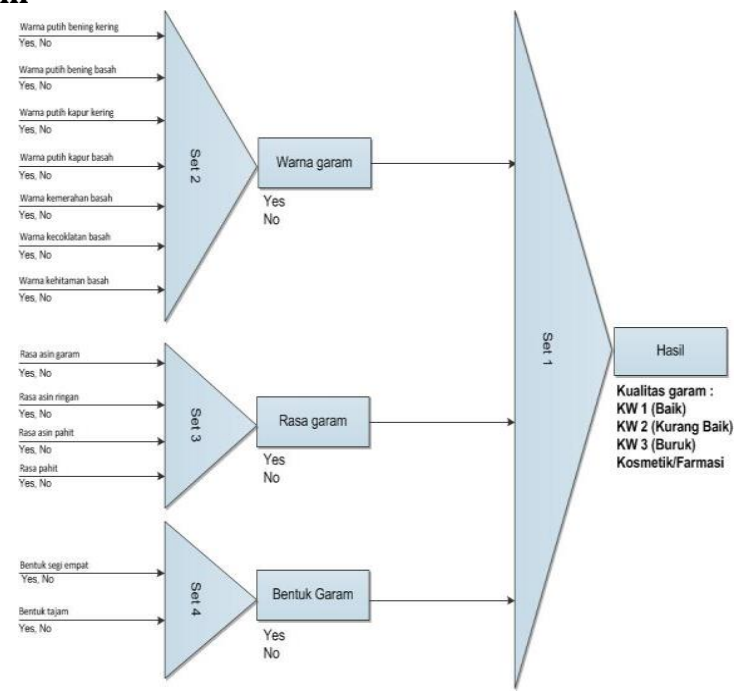

Gambar 2. Dependency Diagram

\section{If Then Rules Set}

\section{Rule 1}

IFWarna putih bening kering ANDRasa asin garam ANDBentuk segi empatTHEN Garam Kualitas KW 1 (Baik)

Rule 2

Rule 15

IF Warna putih bening basah AND Rasa pahit AND Bentuk Tajam THEN Garam Kosmetik atau Farmasi

\section{HASIL DAN PEMBAHASAN}

\subsection{Antarmuka Aplikasi}

\subsubsection{Halaman Menu Riwayat Konsultasi}

Halaman menu riwayat konsultasi berisi tentang konsultasi dari user yang berisi id user, tanggal konsultasi, jenis garam, ciri-ciri garam, kandungan garam dan hasil/kualitas. Pada halaman ini ada tombol view, edit dan delete. Dapat dilihat pada gambar:

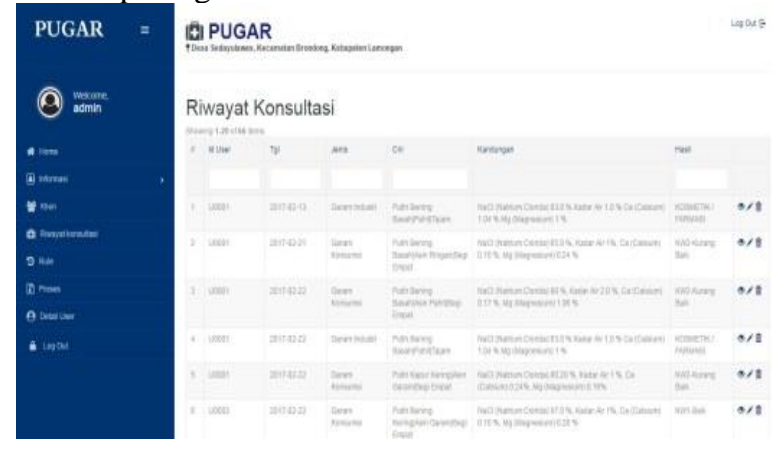

Gambar 3. Halaman Menu Riwayat Konsultasi 


\subsubsection{Halaman Menu Rule}

Halaman menu rule yaitu berisi 15 rule yang digunakan untuk menentukan kualitas garam, yang terdiri dari rule, warna, rasa, bentuk, hasil. Pada halaman ini ada tombol create rule, view, edit dan delete. Dapat dilihat pada gambar dibawa

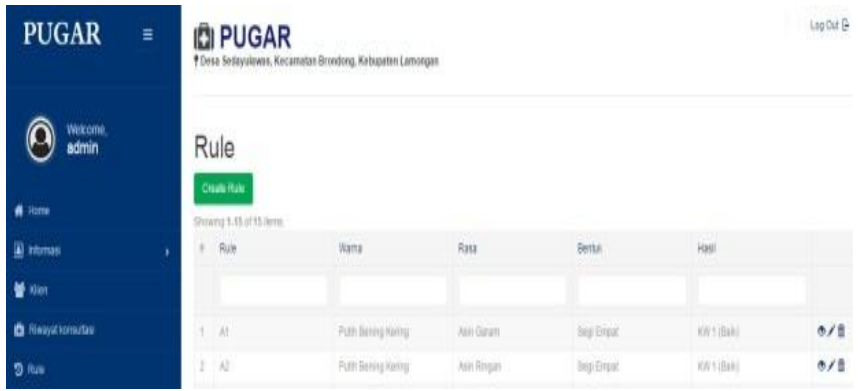

Gambar 4. Halaman Menu Rule Ke-1 sampai ke-2

\subsection{Pengujian Sistem}

Pengujian sistem yang dilakukan menggunakan black box. Berikut ini merupakan hasil dari pengujian sistem yang telah dibangun.

\subsubsection{Pengujian Menu Login}

Berikut ini merupakan Kasus Dan hasil Uji Data Normal dapat dilihat pada tabel dibawah ini:

1. Admin/Pakar

Tabel 4. Hasil Pengujian Proses Login Kasus dan Hasil Uji Data Normal

\begin{tabular}{|l|l|l|l|}
\hline \multicolumn{5}{|c|}{ Kasus Dan Hasil Uji Data Normal } \\
\hline Data Masukan & Yang Diharapkan & Pengamatan & Kesimpulan \\
\hline username : admin & Pada teks username & Pada teks username & \\
& tercantum admin & tercantum admin & \\
Password: & Pada teks password & $\begin{array}{l}\text { Pada teks password } \\
\text { tercantum admin }\end{array}$ & Valid \\
tercantum admin & \\
\hline
\end{tabular}

2. Pandaftaran User

Tabel 5. Hasil Pengujian Proses Login Kasus dan Hasil Uji Data Normal

Kasus Dan Hasil Uji Data Normal

\begin{tabular}{|l|l|l|l|}
\hline Data Masukan & Yang Diharapkan & Pengamatan & Kesimpulan \\
\hline Username: & & & \\
Nama : & Data yang dimasukkan benar & Tampil & \\
Alamat : & kemudian menekan tombol & pendaftara & Valid \\
No Telp : & create dan akan menampilkan & berhasil & \\
Password : & data user & & \\
& & & \\
\hline
\end{tabular}

\subsubsection{Pengujian Penampilan Tiap Halaman}

Berikut ini merupakan pengujian penampilan tiap halaman dapat dilihat pada tabel:

Tabel 6. Pengujian Penampilan Tiap Halaman

\begin{tabular}{|l|l|l|l|}
\hline \multicolumn{5}{|c|}{ Pengujian Penampilan Tiap Halaman } \\
\hline Data Masukan & Yang Diharapkan & \multicolumn{1}{c|}{ Pengamatan } & Kesimpulan \\
\hline $\begin{array}{l}\text { Klik Menu } \\
\text { Utama }\end{array}$ & Menampilkan menu & $\begin{array}{l}\text { Tampil menu untuk menu } \\
\text { yang dipilih }\end{array}$ & Valid \\
\hline $\begin{array}{l}\text { Klik Menu } \\
\text { Informasi }\end{array}$ & $\begin{array}{l}\text { Menampilakan halaman } \\
\text { menu Informasi (sub }\end{array}$ & $\begin{array}{l}\text { Tampil halaman menu } \\
\text { Informasi (sub menu : }\end{array}$ & Valid \\
\hline
\end{tabular}




\begin{tabular}{|c|c|c|c|}
\hline & $\begin{array}{l}\text { menu : tentang pakar, } \\
\text { jenis-jenis } \\
\text { pembuat web) }\end{array}$ & $\begin{array}{l}\text { tentang pakar, jenis-jenis } \\
\text { garam, pembuat web) }\end{array}$ & \\
\hline $\begin{array}{l}\text { Klik Menu } \\
\text { Informasi }\end{array}$ & $\begin{array}{l}\text { Menampilakan halaman } \\
\text { menu Informasi (sub } \\
\text { menu : tentang pakar, } \\
\text { jenis-jenis garam, } \\
\text { pembuat web) }\end{array}$ & $\begin{array}{l}\text { Tampil halaman menu } \\
\text { Informasi (sub menu : } \\
\text { tentang pakar, jenis-jenis } \\
\text { garam, pembuat web) }\end{array}$ & Valid \\
\hline $\begin{array}{l}\text { Klik Sub Menu } \\
\text { Tentang Pakar }\end{array}$ & $\begin{array}{l}\text { Menampilakan halaman } \\
\text { sub menu tentang pakar }\end{array}$ & $\begin{array}{l}\text { Tampil halaman sub menu } \\
\text { tentang pakar }\end{array}$ & Valid \\
\hline $\begin{array}{l}\text { Klik Sub Menu } \\
\text { Tentang Jenis- } \\
\text { jenis Garam }\end{array}$ & $\begin{array}{l}\text { Menampilakan halaman } \\
\text { sub menu tentang jenis- } \\
\text { jenis garam }\end{array}$ & $\begin{array}{l}\text { Tampil halaman sub menu } \\
\text { tentang jenis-jenis garam }\end{array}$ & Valid \\
\hline $\begin{array}{l}\text { Klik Sub Menu } \\
\text { Tentang } \\
\text { Pembuat Web }\end{array}$ & $\begin{array}{lr}\text { Menampilakan } & \text { halaman } \\
\text { sub menu } & \text { tentang } \\
\text { pembuat web } & \end{array}$ & $\begin{array}{l}\text { Tampil halaman sub menu } \\
\text { tentang pembuat web }\end{array}$ & Valid \\
\hline Klik menu klien & $\begin{array}{l}\text { Menampilakan halaman } \\
\text { menu klien }\end{array}$ & $\begin{array}{l}\text { Tampil halaman menu } \\
\text { klien }\end{array}$ & Valid \\
\hline
\end{tabular}

\subsubsection{Pengujian Pengolahan Data Klien}

Tabel 7. Pengujian Pengolahan Data Klien

\begin{tabular}{|l|l|l|l|}
\hline $\begin{array}{l}\text { Data } \\
\text { Masukkan }\end{array}$ & $\begin{array}{l}\text { Yang } \\
\text { Diharapkan }\end{array}$ & Pengamatan \\
\hline $\begin{array}{l}\text { Klik Tombol } \\
\text { Create Klien }\end{array}$ & $\begin{array}{l}\text { Menampikan halaman } \\
\text { create data klien }\end{array}$ & $\begin{array}{l}\text { Tampil halaman create } \\
\text { data klien }\end{array}$ & Valid \\
\hline $\begin{array}{l}\text { Klik Tombol } \\
\text { View }\end{array}$ & $\begin{array}{l}\text { Menampikan halaman } \\
\text { detail data klien }\end{array}$ & $\begin{array}{l}\text { Tampil halaman detail data } \\
\text { klien }\end{array}$ & Valid \\
\hline $\begin{array}{l}\text { Klik Tombol } \\
\text { Update }\end{array}$ & $\begin{array}{l}\text { Menampikan halaman } \\
\text { update data klien }\end{array}$ & $\begin{array}{l}\text { Tampil halaman detail } \\
\text { update data klien }\end{array}$ & Valid \\
\hline $\begin{array}{l}\text { Klik Tombol } \\
\text { Delete }\end{array}$ & Menghapus data klien & Data klien terhapus & Valid \\
\hline
\end{tabular}

\subsubsection{Pengujian Pengolahan Data Riwayat Konsultasi}

Tabel 8. Pengujian Pengolahan Data Riwayat Konsultasi

\begin{tabular}{|l|l|l|l|}
\hline \multicolumn{1}{|c|}{$\begin{array}{c}\text { Data } \\
\text { Masukkan }\end{array}$} & \multicolumn{1}{|c|}{$\begin{array}{c}\text { Yang } \\
\text { Diharapkan }\end{array}$} & \multicolumn{1}{c|}{ Pengamatan } & \multicolumn{1}{c|}{ Kesimpulan } \\
\hline Klik Tombol View & $\begin{array}{l}\text { Menampikan halaman } \\
\text { detail data riwayat } \\
\text { konsultasi }\end{array}$ & $\begin{array}{l}\text { Tampil halaman detail } \\
\text { data riwayat konsultasi }\end{array}$ & Valid \\
\hline $\begin{array}{l}\text { Klik Tombol } \\
\text { Update }\end{array}$ & $\begin{array}{l}\text { Menampikan halaman } \\
\text { update data riwayat } \\
\text { konsultasi }\end{array}$ & $\begin{array}{l}\text { Tampil halaman detail } \\
\text { update data riwayat } \\
\text { konsultasi }\end{array}$ & Valid \\
\hline $\begin{array}{l}\text { Klik Tombol } \\
\text { Delete }\end{array}$ & $\begin{array}{l}\text { Menghapus data } \\
\text { riwayat konsultasi }\end{array}$ & $\begin{array}{l}\text { Data riwayat konsultasi } \\
\text { terhapus }\end{array}$ & Valid \\
\hline
\end{tabular}

\subsubsection{Pengujian Pengolahan Data Rule}

Tabel 9. Pengujian Pengolahan Data Rule

\begin{tabular}{|l|l|l|l|}
\hline $\begin{array}{l}\text { Data } \\
\text { Masukkan }\end{array}$ & $\begin{array}{l}\text { Yang } \\
\text { Diharapkan }\end{array}$ & Pengamatan & Kesimpulan \\
\hline
\end{tabular}




\begin{tabular}{|l|l|l|l|}
\hline $\begin{array}{l}\text { Klik Tombol } \\
\text { CreateRule }\end{array}$ & $\begin{array}{l}\text { Menampikan halaman } \\
\text { create data rule }\end{array}$ & $\begin{array}{l}\text { Tampil halaman create } \\
\text { data rule }\end{array}$ & Valid \\
\hline Klik Tombol View & $\begin{array}{l}\text { Menampikan halaman } \\
\text { detail data rule }\end{array}$ & $\begin{array}{l}\text { Tampil halaman detail } \\
\text { data rule }\end{array}$ & Valid \\
\hline Klik Tombol Update & $\begin{array}{l}\text { Menampikan halaman } \\
\text { update data rule }\end{array}$ & $\begin{array}{l}\text { Tampil halaman } \\
\text { detailupdate data rule }\end{array}$ & Valid \\
\hline Klik Tombol Delete & Menghapus data rule & Data rule terhapus & Valid \\
\hline
\end{tabular}

\subsubsection{Pengujian Proses Konsultasi}

Tabel 10. Pengujian Proses Konsultasi

\begin{tabular}{|c|c|c|c|}
\hline $\begin{array}{l}\text { Data } \\
\text { Masukkan }\end{array}$ & $\begin{array}{l}\text { Yang } \\
\text { Diharapkan }\end{array}$ & Pengamatan & Kesimpulan \\
\hline Klik Menu Proses & $\begin{array}{ll}\text { Menampikan } & \text { ciri-ciri } \\
\text { garam (warna } & \text { garam, } \\
\text { rasa garam, } & \text { bentuk } \\
\text { garam) } & \end{array}$ & $\begin{array}{l}\text { Tampil ciri-ciri garam } \\
\text { (warna garam, rasa } \\
\text { garam, bentuk garam) }\end{array}$ & Valid \\
\hline $\begin{array}{l}\text { Klik Warna Garam Putih } \\
\text { Bening Kering, Rasa } \\
\text { Garam Rasa Asin } \\
\text { Garam, Bentuk Garam } \\
\text { Bentuk Segi Empat }\end{array}$ & \begin{tabular}{lcr}
\multicolumn{2}{l}{ Menampikan } & Warna \\
Garam & Putih & Bening \\
Kering, & Rasa & Garam \\
Rasa & Asin & Garam, \\
Bentuk & Garam & Bentuk \\
\multicolumn{2}{l}{ Segi Empat }
\end{tabular} & $\begin{array}{l}\text { Tampil Warna Garam } \\
\text { Putih Bening Kering, } \\
\text { Rasa Garam Rasa Asin } \\
\text { Garam, Bentuk Garam } \\
\text { Bentuk Segi Empat }\end{array}$ & Valid \\
\hline Klik Tombol Proses & $\begin{array}{ll}\text { Menampikan } & \text { Hasil } \\
\text { Kualitas Garam } & \end{array}$ & $\begin{array}{lll}\text { Tampil Hasil Kualitas } \\
\text { Garam }\end{array}$ & Valid \\
\hline
\end{tabular}

Berdasarkan hasil pengujian dengan menggunakan black box maka sistem pakar untuk menentukan kualitas garam berjalan sesuai dengan yang diharapkan (100\%).

\section{KESIMPULAN DAN SARAN}

Darihasil dependency diagram dapat dijelaskan bahwa data menunjukan kondisi yang mempengaruhi rule set 2 , set 3 , dan set 4 dari kondisi tersebut menghasilkan kesimpulan awal berupa warna garam, rasa garam dan bentuk garam. Selanjutnya, hasil yang berasal dari rule set 2 , set 3 , dan set 4 membentuk rule set 1 sehingga data rule set 1 terdapat basis pengetahuan berupa aturan yang telah diklasifikasi yang menghasilkan output berupa identifikasi kualitas yaitu KW 1 (Baik), KW 2 (Kurang Baik), KW 3 (Buruk), Kosmetik/Farmasi.

Metode forward chaining dapat digunakan untuk menentukan kualitas garam, yang dimulai dari faktafakta yang ada kemudian diperoleh hasil/kesimpulan. Dalam penelitian ini terdapat 3 parameter yang digunakan untuk menentukana kualitas garam yaituwarna garam, rasa garam, bentuk garam. Pengujian dilakukan denganuji black boxmenggunakan 5 parameter uji system yaitu Pengujian menu login, tampilan tiap halaman, pengelolaan data klien, riwayat konsultasi, pengelolaan data rule, dan proses konsultasi maka didapat hasil pengujian dengan prosentase $100 \%$ valid.

\section{DAFTAR RUJUKAN}

[1] Burhanuddin. Proceeding Forum Pasar Garam Indonesia. Jakarta. Badan Riset Kelautan dan Perikanan. 2001.

[2] Hayadi, Hermawan.Sistem Pakar (Penyelesaian Kasus Menentukan Minat Baca, Kecenderungan, dan Karakter Siswa dengan Metode Forward Chaining. Yogyakarta. Deepublish. 2016.

[3] Ishak, Zunaidi, M., Saniman,.Jurnal Ilmiah SAINTIKOM Vol. 12, No. 3 - Rule Base Expert System Dengan Metode Forward Chaining Untuk Memprediksi Kualitas Kain Batik. Medan. STMIK Triguna Dharma. 2013.

[4] Kusrini.Aplikasi Sistem Pakar. Yogyakarta. Andi Offset. 2006. 
[5] Kusrini.Tuntunan Praktis Membangun Sistem Informasi Akuntansi Dengan Visual Basic dan Microsoft SQL Server. Yogyakarta. Andi Offset. 2007.

[6] Kusumadewi, Sri. Artificial Intelligence (Teknik dan Aplikasinya).Yogyakarta. Graha Ilmu. 2003.

[7] Kusumadewi, Sri. Sistem Pakar. Yogyakarta. Graha Ilmu. 2003.

[8] Pujiastuti. Kualitas Produksi Garam dan Mutu Garam. Yogyakarta. Graha Ilmu. 2008.

[9] Raharjo, Budi. Belajar Otodidak Membuat Database Menggunakan MySQL. Bandung. Penerbit INFORMATIKA. 2011.

[10] ST, Anhar. Panduan Menguasai PHP dan My SQL Secara Otodidak. Jakarta Selatan. Media Kita. 2010.

[11]T, Soejoto. Metode Forward Chaining. Yogyakarta. Graha Ilmu. 2010. 